\title{
Analysis of the electrical energy intensity under energy efficiency actions
}

\author{
López Pereiro D. ${ }^{1}$, Zaragoza S. ${ }^{2}$, Tarrío J. ${ }^{3}$, Naya S. ${ }^{4}$ and Álvarez A.
}

${ }^{1}$ Departamento de Ingeniería Industrial II

Universidad de A Coruña

C/Mendizabal sn 15401 Ferrol -A Coruña (Spain)

Phone/Fax number:+0034 981 337400, e-mail: diego.lopez.pereiro@udc.es

\author{
${ }^{2}$ Departamento de Ingeniería Industrial II \\ Universidad de A Coruña \\ C/Mendizabal sn 15401 Ferrol -A Coruña (Spain) \\ Phone/Fax number:+0034 981 337400, e-mail: szaragoza@udc.es \\ ${ }^{3}$ Departamento de Matemáticas \\ Universidad de A Coruña \\ C/Mendizabal sn 15401 Ferrol -A Coruña (Spain) \\ Phone/Fax number:+0034 981 337400, e-mail: jtarrio@udc.es \\ ${ }^{4}$ Departamento de Matemáticas \\ Universidad de A Coruña \\ C/Mendizabal sn 15401 Ferrol -A Coruña (Spain) \\ Phone/Fax number:+0034 981 337400, e-mail: salva@udc.es \\ ${ }^{5}$ Departamento de Ingeniería Naval y Oceánica \\ Universidad de A Coruña \\ C/Mendizabal sn 15401 Ferrol -A Coruña (Spain) \\ Phone/Fax number:+0034 981 337400, e-mail: aalvarez@udc.es
}

\begin{abstract}
This paper shows the real benefits of energy efficiency if they are regulated by energy indicators on electricity end-use in a industrial warehouse under the Spanish tariff regime.
\end{abstract}

\section{Key words}

Efficiency Energy, energy management, final energy, energy, control management.

\section{Introduction}

One of the main objectives of the European Union (EU) is the reduction of energy consumption and energy waste prevention. To promote the improvement of energy efficiency, the EU contributes to competitiveness, security of supply and environmental respect. In late 2006 the EU [1] promised to save $20 \%$ of the annual primary energy consumption until 2020. In 2011 calculations concluded that to the rhythm of energy expenditure at the end of the decade, there will be only achieved an improvement of $9 \%$ of the $20 \%$ committed.
To avoid this failure, comes a new directive: DIRECTIVE 2012/27 / EU OF THE EUROPEAN PARLIAMENT AND OF THE COUNCIL [2] October 25, 2012, directive ascends to national status in various royal decrees binding on the Spanish state.

Currently there are several indicators that measure energy efficiency, one of the most used is the energy intensity (EI). EI is calculated as the consumption of primary or final energy per unit of gross domestic product (GDP). High energy intensity implies worse energy efficiency because they consume more and spend more to produce the same. An improvement in energy efficiency means a reduction in energy intensity [3]. So that produces more in a country with lower consumption expenditure and environmental impact [4]. 


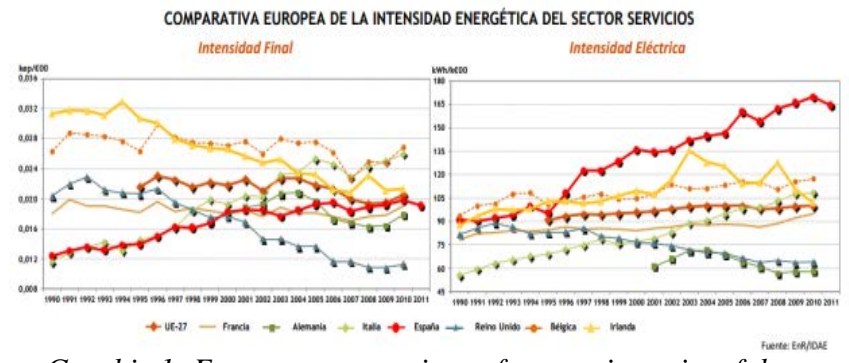

Graphic 1: European comparison of energy intensity of the service sector. Source: IDAE

As shown in the graphs of the Institute for Energy Diversification [5], the electrical energy intensity in the service sector in Spain is increasing every year, this slowing effect since 2008 because of the energy crisis.

Because of this situation, the development of research activities in the field of energy efficiency is promoted.

In this sense the company FRIDAMA SL, a company of air conditioning and electricity, developed together with the University of A Coruña a prototype web application for remote control, maintenance and management of its facilities.

\section{Objective}

The objective of this paper is to show the effect of various energy indicators taking energy efficiency actions on the control of electrical installations in real industrial warehouse located in Spain.

\section{Procedure}

We proceed to the automation of air conditioning and lighting, along with the control and monitoring of energy variables such as temperature, relative humidity, CO2 levels, consumption facilities climate, lighting, office, ...

A web application for review and control management and automation of facilities is developed.

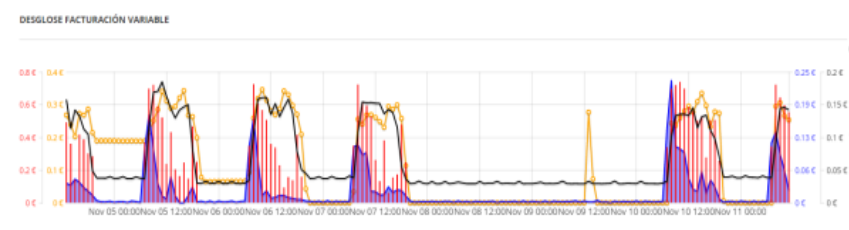

Figure 1: Example of facturation graph from web application.

Through the records we took the decision to implement automatic time control measures of on and off, producing power facilities at 8 am to $7 \mathrm{pm}$, except the air conditioning which turns on and turns off one hour before. We also perform including photocells for lighting control consumption, as energy efficiency actions.

To test the effectiveness of these, we study the most suitable energy intensity indicator, which in this case is to check the evolution of expenditure on electricity by industrial warehouse before and during takes energetic measures described above.

\section{Indicator energy analysis}

\subsection{Rate analysis.}

Before analyzing billing ensuring the correct operation of the facility according RITE [6], the graphs of the evolution are shown for the desired period, in this case is from December 2012 to September 2014, prices in the market power, both the power (graphic 2) and the cost of energy (graphic 3).

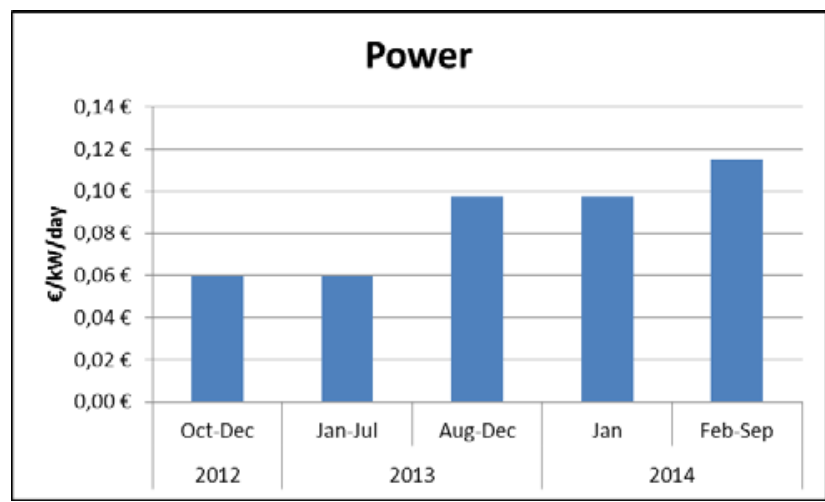

Graphic 2: Evolution of cost of power

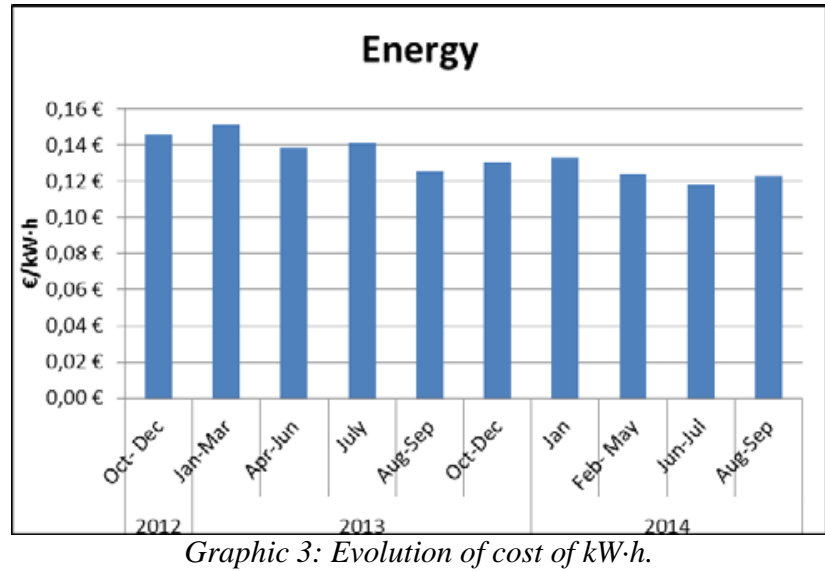

The previous graphics shows stability in the price of energy, which is only a 3 cents variation range. By contrast, the power was increased gradually from almost 6 cents in December 2012 to 11.5 cents in May 2014, which continues to the present.

Next, in graphic 4, a comparison is made, in percent, of what represents each of the basic terms of electricity in the bill, which is the power and energy consumed. 


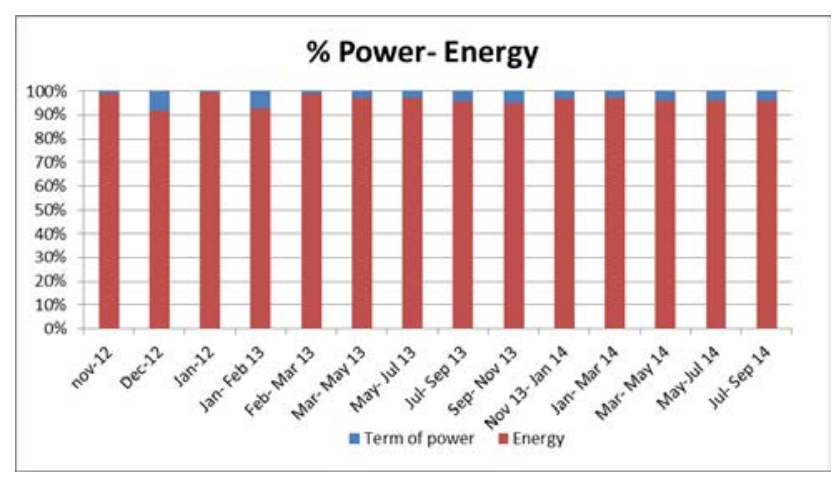

Graphic 4: Ratio of fixed and variable costs in the electricity invoice.

Until February 2013, the facturation was monthly, but the reading was done bimonthly, which performed an estimate of consumption in the month that did not make the reading, so the asymmetry can be seen in the first four data of graphics 4 and 5 .

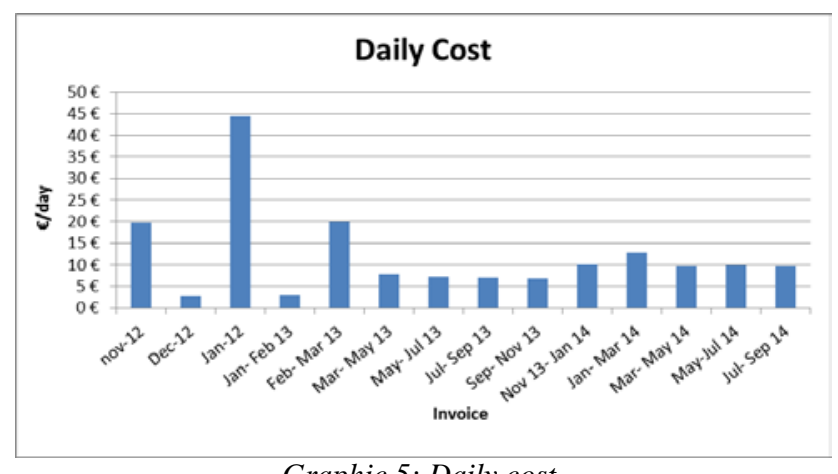

Graphic 5: Daily cost.

This study is necessary to distinguish between increases in billing due to internal causes or rate regime.

\subsection{Consumption Analysis}

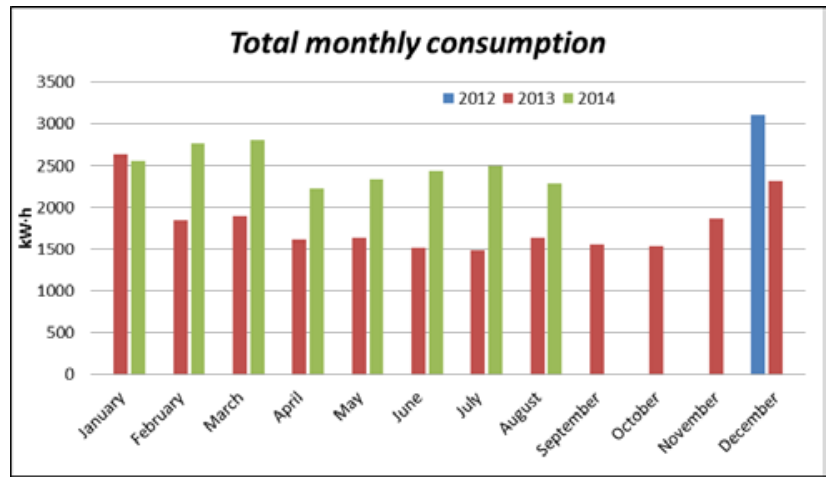

Graphic 6: Total monthly consumption.

The graph above is done by prorating consumption billing periods to accommodate the calendar months of the year and be able to make an effective comparison of such consumption.

Below is a graph of the average daily consumption between December 2012 and September 2014 performed, where you can clearly see the increase in consumption from February 2014.

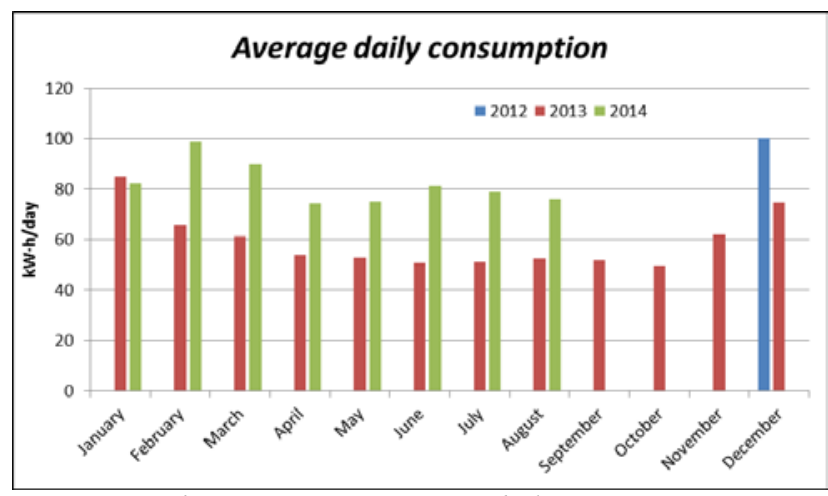

Graphic 7: Compare average daily consumption.

To make the above graph, we calculated the daily averages for each month. To do this, the calculations of the monthly consumption for periods were performed and, from these, the daily calculations. Subsequently, an assessment was made of consumption to suit each calendar month of the year.

- $\quad$ Year 2013

As you can see in the chart above, in 2013 there are three distinct trends: decreased consumption until April, a horizontal period up to October and consumption growth from October.

\section{- $\quad$ Year 2014}

A similar trend is seen with the previous year, despite not being able to affirm fully due to lack of data. Since February, a jump in consumption occurs, due in all probability to the works undertaken for the expansion of facilities. We also note that in 2014, the overall daily consumption of the plant, have a significantly increase an average of about $25 \mathrm{~kW} \cdot \mathrm{h}$ per day since February, compared to the year 2013, and with total security is due to the increased size of the office and to the increase staff in it. In the following table we can see these variations mentioned, in percent.

Table 1: Consumption from January to August and annual difference $(\mathrm{kW} \cdot \mathrm{h} /$ day).

\begin{tabular}{|cccc|}
\hline Month & 2013 & 2014 & Difference \\
\hline February & 66,0 & 99,0 & $50 \%$ \\
\hline March & 61,3 & 90,2 & $47 \%$ \\
\hline April & 53,8 & 74,3 & $38 \%$ \\
\hline May & 52,8 & 74,3 & $41 \%$ \\
\hline June & 50,7 & 81,2 & $60 \%$ \\
\hline July & 51,2 & 79,0 & $54 \%$ \\
\hline August & 52,7 & 76,0 & $44 \%$ \\
\hline
\end{tabular}

From the above table, we find that the average plant consumption has increased in order of 48\% in 2014 over the previous year. 
Making an analysis of the consumption from energy indicator of consumption per person and consumption per surface, we obtain the results shown below.

Table 2: Consumption per person between the months of March and August.

\begin{tabular}{|cccc|} 
Month & 2013 & 2014 & Difference \\
\hline March & 8,75245074 & 6,94103051 & $-21 \%$ \\
\hline April & 7,6893424 & 5,71493213 & $-26 \%$ \\
\hline May & 7,54278777 & 5,78378227 & $-23 \%$ \\
\hline June & 7,23502304 & 6,24852071 & $-14 \%$ \\
\hline July & 7,32018093 & 6,07978622 & $-17 \%$ \\
\hline August & 7,52834467 & 5,84615385 & $-22 \%$ \\
\hline
\end{tabular}

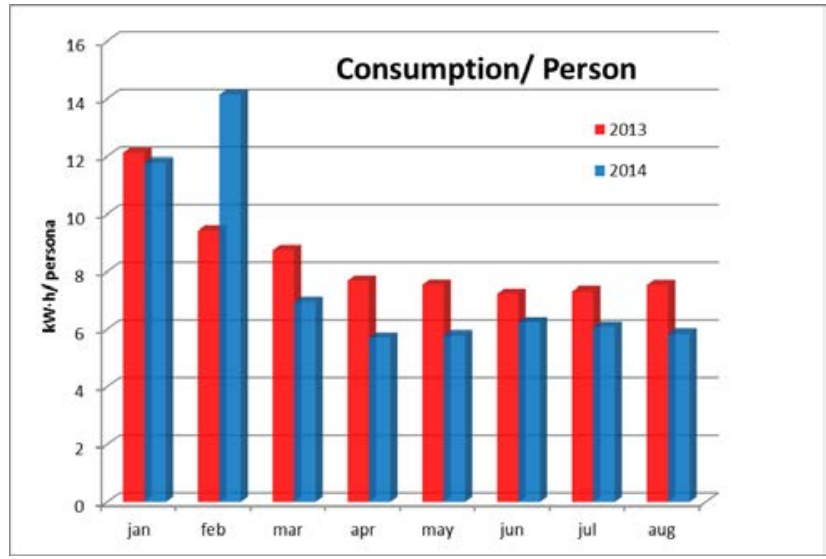

Graphic 7: Daily consumption per person in 2013 and 2014, between January and August.

As shown in the above table and graph, we can see a clear decrease in consumption per person from February 2014, the month in which the work in office was performed, and a consumption peak is observed in this month in Figure 7.

In the table we also observe the percentage differences in consumption, which indicates that since February, consumption per person has decreased an average of about $20 \%$.

This shows that the energy savings that occurs after taking energy efficiency actions that results in a clear cost savings.

\section{Conclusions}

The power prices have increased significantly since the almost 6 cents in December 2012 to 11.5 cents in September 2014. Although this does not imply a large impact on the invoice because the power implies less 5\% of the same.

The cost of energy has changed little in recent months, even declined slightly. Note that accounts for almost 95\% of the bill, which is where you should concentrate on saving, using energy efficient methods.
As for energy consumption, as we can see in the previous graphs, as we approach the colder months of the year, increases the energy consumption of the plant as a result of the heating needs of the same.

In 2014, global consumption of the plant significantly increases an average of about $25 \mathrm{~kW} \cdot \mathrm{h}$ per day since February, compared to 2013. This represents an average increase of $48 \%$ in 2014 compared to 2013.

Looking at consumption per person, which is the most reliable when it comes to assessing the impact of the actions taken to save energy, we see that consumption per person is reduced on the order of $20 \%$, indicating us favorable impact of these energy efficiency actions.

The consumption in February 2014, is significantly, away from the trend, because surely an extraordinary action on the ground.

\section{Acknowledgments}

This work was partially funded by project MTM 201122393 (ERDF included) and EN E2013-48015-C3-1-R

\section{References}

[1] ES CE. Directive 2006/32 / EC on energy end use efficiency and energy services, from April 5, 2006.

[2] ES CE. Directive 2012/27 / EC on energy efficiency, October 25, 2012.

[3] Greening, L. A., Greene, D. L. y Difiglio, C. Energy efficiency and consumption -the rebound effect- a survey, Energy Policy, 28, 389-401, 2000.

[4] Crosbie, T. y Baker, K. Energy-efficiency interventions in housing: learning from the inhabitants, Building research \& information, 38, 70-79, 2010.

[5] IDAE Instituto para la diversificación y ahorro de energía. Available: http://www.idae.es/[2011]

[6] ES Ministerio de la Presidencia. RITE. Real Decreto 1027/2007 de 2007 de julio. Madrid: ES. Reglamento de Instalaciones térmicas en los edificios, 2007 